\title{
Reduced fractional anisotropy and axial diffusivity in white matter in 22q11.2 deletion syndrome: $A$ pilot study
}

\section{Citation}

Kikinis, Z., T. Asami, S. Bouix, C.T. Finn, T. Ballinger, E. Tworog-Dube, R. Kucherlapati, R. Kikinis, M.E. Shenton, and M. Kubicki. 2012. Reduced Fractional Anisotropy and Axial Diffusivity in White Matter in 22q11.2 Deletion Syndrome: A Pilot Study. Schizophrenia Research 141, no. 1: 35-39. doi:10.1016/j.schres.2012.06.032.

\section{Published Version}

doi:10.1016/j.schres.2012.06.032

\section{Permanent link}

http://nrs.harvard.edu/urn-3:HUL.InstRepos:28548730

\section{Terms of Use}

This article was downloaded from Harvard University's DASH repository, and is made available under the terms and conditions applicable to Other Posted Material, as set forth at http:// nrs.harvard.edu/urn-3:HUL.InstRepos:dash.current.terms-of-use\#LAA

\section{Share Your Story}

The Harvard community has made this article openly available.

Please share how this access benefits you. Submit a story.

Accessibility 
Published in final edited form as:

Schizophr Res. 2012 October ; 141(1): 35-39. doi:10.1016/j.schres.2012.06.032.

\title{
Reduced Fractional Anisotropy and Axial Diffusivity in White Matter in 22q11.2 Deletion Syndrome: A Pilot Study
}

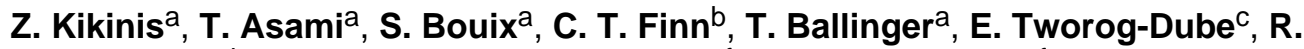 \\ Kucherlapati $^{d}$, R. Kikinis ${ }^{e}$, M. E. Shenton ${ }^{a, e, f}$, and M. Kubicki ${ }^{a, e, f}$ \\ apsychiatry Neuroimaging Laboratory, Department of Psychiatry, Brigham and Women's Hospital, \\ Harvard Medical School, Boston, MA,USA \\ ${ }^{b}$ Department of Psychiatry, Dartmouth Hitchcock Medical Center, Lebanon, NH, USA \\ 'Department of Medicine, Brigham and Women's Hospital, Harvard Medical School, Boston, MA, \\ USA
}

dDepartment of Genetics, Harvard Medical School, Boston, MA, USA

eSurgical Planning Laboratory, Department of Radiology, Brigham and Women's Hospital, Harvard Medical School, Boston, MA, USA

fClinical Neuroscience Division, Laboratory of Neuroscience, Department of Psychiatry, VA Boston Healthcare System, Harvard Medical School Brockton, MA, USA

\begin{abstract}
Individuals with 22q11.2 deletion syndrome (22q11.2DS) evince a $30 \%$ incidence of schizophrenia. We compared the white matter (WM) of 22q11.2DS patients without schizophrenia to a group matched healthy controls using Tract-Based-Spatial-Statistics (TBSS). We found localized reduction of Fractional Anisotropy (FA) and Axial Diffusivity (AD; measure of axonal integrity) in WM underlying the left parietal lobe. No changes in Radial Diffusivity (RD; measure of myelin integrity) were observed. Of note, studies in chronic schizophrenia patients report reduced FA, no changes in AD, and increases in RD in WM. Our findings suggest different WM microstructure in 22q11.2DS than in patients with schizophrenia.
\end{abstract}

\section{Keywords}

22q11.2 deletion syndrome (22q11.2DS); schizophrenia; Diffusion Tensor Magnetic Resonance Imaging (DT-MRI); fractional anisotropy (FA); axial and radial diffusivity; Tract-Based Spatial Statistics (TBSS)

\footnotetext{
(C) 2012 Elsevier B.V. All rights reserved.

Correspondence: Zora Kikinis, Ph.D., Psychiatry Neuroimaging Laboratory, Department of Psychiatry, Brigham and Women's Hospital, 1249, Boylston Street, Boston, MA 02115;, zora@bwh.harvard.edu, phone: 617-525-6116, FAX: 617-525-6150..

Publisher's Disclaimer: This is a PDF file of an unedited manuscript that has been accepted for publication. As a service to our customers we are providing this early version of the manuscript. The manuscript will undergo copyediting, typesetting, and review of the resulting proof before it is published in its final citable form. Please note that during the production process errors may be discovered which could affect the content, and all legal disclaimers that apply to the journal pertain.

Contributors: Z. Kikinis, S. Bouix, R. Kikinis, M.E. Shenton and M. Kubicki designed the imaging study and wrote the protocol. T. Asami and T. Ballinger advised and performed image analysis. C.T. Finn, E. Tworog-Dube and R. Kucherlapati recruited the patients and provided feedback on the study patients as well as providing their expertise in 22q11.2DS. Z. Kikinis wrote the manuscript. All authors contributed to, and have approved, the manuscript.
}

Conflict of interest

None of the authors have a financial conflict of interest regarding this report. 


\section{Introduction}

22q11 deletion syndrome (22q11.2DS), also known as Velo-cardio-facial syndrome (VCFS) (Shprintzen, 2008), is a rare disease caused by a deletion in chromosome 22 . Up to $30 \%$ of patients with this diagnosis suffer from schizophrenia, thus making the syndrome a target for the exploration of factors that lead to psychosis (Chow et al., 2011; da Silva Alves et al., 2011; Gothelf et al., 2007b; Kates et al., 2011; van Amelsvoort et al., 2004).

Effects in humans include schizophrenia (Bassett et al., 2005; Murphy et al., 1999), learning disabilities (Murphy et al., 1998), autism (Niklasson et al., 2009), depression (Green et al., 2009), and bipolar disorder (Papolos et al., 1996). The exact cause of this high comorbidity is not known, but the frequently occurring dysmorphology of heart, limbs (short statue), face and brain suggests a developmental disorder involving cells of the neural crest (Kirby et al., 1983). 22q11.2DS is characterized by a microdeletion of 30-45 genes on chromosome 22. Studies in a 22q11.2DS mouse model (LgDel mouse) demonstrate that reduced expression of several of these genes results in abnormalities in the number, location and connectivity of neurons in the developing brain (Meechan et al., 2010).

One of the most influential hypotheses in schizophrenia suggests abnormalities in brain connectivity (Konrad and Winterer, 2008). Abnormal brain connectivity in schizophrenia is now supported by changes in white matter (WM) fiber tracts (Ellison-Wright and Bullmore, 2009; Kubicki et al., 2007), as well as by abnormalities in neural circuitry, which are based on fMRI studies(Deserno et al., 2012). Additionally, altered oligodendroglial cells, decreased myelination of fibers, and changes in the expression of myelin-related genes have all been associated with schizophrenia (e.g., (Davis et al., 2003; Hakak et al., 2001; Tkachev et al., 2003; Uranova et al., 2001), suggesting abnormalities in myelin in this disorder. Interestingly, while DT-MRI studies in 22q11.2DS patients also report abnormalities in WM integrity (Barnea-Goraly et al., 2003; da Silva Alves et al., 2011; Simon et al., 2008;

Sundram et al., 2010), animal studies point to neurons and their axons, rather than myelin, as the possible source of observed WM abnormalities in 22q11.2DS (Meechan et al., 2010).

The method used in general today to explore WM, in vivo, is Diffusion Tensor Magnetic Resonance Imaging (DT-MRI). The majority of DT-MRI studies use Fractional Anisotropy (FA) for quantification. FA is a measure that describes the directionality of water diffusion. Its value ranges from 0 to 1 , with a value of 0 corresponding to a perfectly isotropic environment, where water is unrestricted as for example in cerebrospinal fluid, and with a value of 1 corresponding to a perfect anisotropic environment, where water is most restricted in all but one direction, as for example in WM fiber bundles (Basser et al., 1994). More specifically, FA has higher values in WM, where myelinated axons are highly organized. Here, water diffusion is believed to be hindered by barriers (i.e., anisotropic), such as the membranes, myelin and cytoskeleton (Beaulieu, 2002). Nevertheless, while FA is sensitive to all changes in WM micro and macro structure, it is very nonspecific when it comes to tissue pathology. Other DTI indices, however, such as parallel diffusivity (also known as axial diffusivity or AD) and perpendicular diffusivity (also known as radial diffusivity or RD), are believed to be more specific to underlying micropathology. These measures have, in fact, been shown to be markers of axonal (AD) and myelin (RD) integrity in a series of mouse experiments (Song et al., 2003; Song et al., 2005). AD and RD measures have also subsequently been applied to clinical populations in order to study adolescent development (e.g.,(Giorgio et al., 2010), aging (Van Hecke et al., 2008), cerebral tumors (Nagesh et al., 2008), multiple sclerosis (Klawiter et al., 2011; Roosendaal et al., 2009), autism (Barnea-Goraly et al., 2010), schizophrenia (Ashtari et al., 2007; Seal et al., 2008; Whitford et al., 2010), and 22q11.2DS (Simon et al., 2008)). 
In this study we investigate differences in WM pathology between adult 22q11.2DS patients without schizophrenia and matched healthy controls using DT-MRI. Group comparisons are performed using Tract-Based Spatial Statistics (TBSS) (Smith et al., 2006), a method that allows for hypothesis-free voxel-based whole brain WM group comparisons. TBSS is a new generation of voxel-based methods that instead of performing statistical group analysis for each voxel of the WM, compares only voxels that belong to large fiber bundles. This requires that only correspondence between major tracts across all subjects needs to be established, which minimizes registration errors, and reduces partial volume effects.

Based on the high risk of schizophrenia in 22q11.2DS patients, we hypothesize that our patients with 22q11.2DS will be characterized by reduced FA, which is similar to WM changes observed in schizophrenia patients and in subjects at ultra high risk for schizophrenia (Carletti et al., 2012). We further hypothesize that either increases in RD (indicative of abnormalities in myelin as suggested by imaging and nonimaging schizophrenia studies), or decreases in AD (indicative of axonal changes as suggested by 22q11.2DS mouse model) will account for FA abnormalities.

\section{Methods}

\subsection{Subjects}

Nine subjects with 22q11.2DS and nine healthy subjects, group matched for age, gender and PSES, were included in this study (Table 1). Deletion of the chromosomal region 22q11.2 was reconfirmed by Fluorescent-In-Situ-Hybridization (FISH) in the patient group. Patients were recruited from a multidisciplinary 22q11.2DS treatment program at Brigham and Women's Hospital, Children's Hospital, and Massachusetts General Hospital, Boston, MA, and through advertisements placed on 22q11.2DS related websites. Healthy subjects were recruited through local newspaper advertisements. All patients were evaluated for psychiatric disorders using medical charts and Structured Clinical Interview for DSM-IV and none were diagnosed with schizophrenia or schizophrenia episodes at the time of the scan. Two patients were receiving antipsychotic medications at the time of scan, risperdal and seroquel, respectively, at low doses to manage anxiety and insomnia. Healthy subjects were screened using the Structured Clinical Interview (SCID non-patient edition) (Spitzer, 1990). No control subjects had an Axis I psychiatric disorder or a first-degree relative with an Axis I psychiatric disorder. Exclusion criteria for the control subjects were: history of neurologic illness or major head trauma, electroconvulsive therapy, alcohol or drug dependence in the last 5 years, and/or significant alcohol or drug abuse within the last year. The study was approved by local institutional IRBs at Children's Hospital, Massachusetts General Hospital, and Brigham and Women's Hospital. All subjects signed informed consent prior to study participation.

\subsection{Diffusion-weighted scans}

were acquired using line scan diffusion imaging (LSDI) (Gudbjartsson et al., 1996) on a 1.5 Tesla System GE Echospeed scanner. We used an imaging protocol described in previous publications (Kubicki et al., 2004; Rosenberger et al., 2008). Briefly, after obtaining Line Scan Diffusion Tensor Images of the entire brain $(1.7 \times 1.7 \times 4 \mathrm{~mm}$ coronal slices, 6 gradient directions with $\mathrm{B}=1000,2 \mathrm{~B} 0$ scans), tensors were estimated using the least square method (Mangin et al., 2002), and FA, AD and RD were calculated using 3DSlicer software (http:// www.slicer.org/).

\subsection{Data Analysis}

Voxel-based comparisons of FA, AD and RD were performed using TBSS software version v1.2 (http://www.fmrib.ox.ac.uk/fsl/tbss/index.html), and standard processing steps were 
followed. The number of permutations was set at 5000 and the significance level was set at Family-Wise Error (FWE) corrected at $p<0.05$. Tracts were identified by John Hopkins University (JHU) White-Matter-Tractography-Atlas (Wakana et al., 2007). To present the range of diffusivities within groups and specific regions, and to perform correlations, the 4D skeleton was split into individual images, which were then imported into 3DSlicer software. Region specific comparisons and correlations were performed only for the region that showed significant group differences in TBSS.

\subsection{Statistical analysis}

The Statistical Package for Social Sciences (PASW-version-17.0) was used to perform ttests of the socio-demographic data and statistics for diffusivities. Correlations between FA, $\mathrm{AD}$ and handedness were evaluated using Spearman's Rho. Because of the small sample size, we also calculated effect size and statistical power (Faul et al., 2009).

\section{Results}

FA was compared between 22q11.2DS and controls using a whole brain voxel-by-voxel approach, TBSS, to evaluate localized WM abnormalities. Only one region of the cerebrum showed statistically significant reductions of $F A\left(t>=3, P<0.05_{\text {corrected }}\right)$, and this was localized to left parietal lobe WM (Figure 1), where the inferior fronto-occipital fasciculus (IFOF), the inferior longitudinal fasciculus (ILF), the superior longitudinal fasciculus (SLF), cingulum and anterior thalamic radiation intersect. Interestingly, the same region, albeit more extended, showed statistically significant group differences for AD (Figure 1). No significant changes in RD were detected.

FA and $\mathrm{AD}$ were further quantified in each subject in the region of FA reductions and presented in scatter plots (Figure 2). FA and AD showed statistically significant group differences $(\mathrm{p}<0.001)$, as described in the TBSS analysis, above.

Effect sizes for FA (Cohen's d=2.846, effect size $\mathrm{r}=0.8181$ ) and $\mathrm{AD}(\mathrm{d}=2.300, \mathrm{r}=0.7547)$ are large. Power is higher than $99 \%$ for both measures, indicating that even with small sample sizes, both FA and AD are powerful indicators of group membership.

Lateralization of group differences to the left hemisphere was not associated with handedness (Spearman's rho coefficient for 22q11.2DS group and FA: $r=-0.2, P=0.7, n=7$; for controls and FA: $\mathrm{r}=-0.4, \mathrm{P}=0.3, \mathrm{n}=8$; for 22q11.2DS and $\mathrm{AD} \mathrm{r}=-0.1, \mathrm{P}=0.8, \mathrm{n}=7$; for controls and AD: $r=-0.3, P=0.5, n=8)$.

\section{Discussion}

Changes in major WM tracts were investigated in 22q11.2DS using whole brain TBSS, a method that has not previously been applied to this population. Findings revealed FA reductions in left parietal lobe WM, where several WM tracts, including IFOF, ILF, SLF, cingulum and thalamic radiation intersect. Reduced $A D$ values, but not $R D$ changes were observed. These findings suggests axonal, rather than myelin disruption.

Four other studies have used DT-MRI to analyze WM in 22q11.2DS (Barnea-Goraly et al., 2003; da Silva Alves et al., 2011; Simon et al., 2008; Sundram et al., 2010). These studies used an earlier voxel-based morphometry technique (VBM) and reported WM abnormalities within the fronto-parietotemporal connections, anatomical locations similar to those observed in our study. All of these studies used FA, which is a sensitive but nonspecific DTI measure, as it does not provide further characterization of the microstructural nature of these abnormalities (i.e., myelin disruption vs. axonal pathology). Our study uses RD and AD as 
measures of myelin and axon integrity, and is the first to suggest axonal impairments as the basis of the observed WM abnormalities in 22q11.2DS.

Compared to 22q11.2DS, WM abnormalities in schizophrenia are better documented. Over 100 DT-MRI studies have been published to date, and most report FA reductions in schizophrenia (findings summarized in (Ellison-Wright and Bullmore, 2009; Melonakos et al., 2011)). Several studies of schizophrenia have also used RD and AD measures to characterize further the microstructural nature of FA anomalies (Ashtari et al., 2007; Seal et al., 2008; Whitford et al., 2010), including Seal et al. (2008), who performed TBSS analysis, reporting $\mathrm{RD}$, but no AD differences in schizophrenia. Since our study demonstrates changes in $\mathrm{AD}$, but no changes in RD in $22 \mathrm{q} 11.2 \mathrm{DS}$, we view this as a very important distinction and for evidence that brains of patients with schizophrenia and patients with 22q11.2DS share macro, but not micro-structural features of WM pathology.

More specifically, both patients groups, those with 22q11.2DS and those with schizophrenia, demonstrate FA reduction in fronto-temporal connections. However, while WM myelin (RD) seems to be affected in schizophrenia, and intact in 22q11.2DS, axonal abnormalities (AD) exist in 22q11.2DS but not in schizophrenia. Decreased AD, which we observe here, might suggest thinner axons (reduced axonal caliber and overexpression of neurofilaments and III beta-tubulin (Harsan et al., 2006), less well ordered axons (as a consequence of periventricular nodular heterotopias and displaced neurons scattered in the WM, likely a consequence of misguided cell migration during development (Kiehl et al., 2009)) or lower number of axons (Meechan et al., 2010). These apparent differences between schizophrenia and 22q11.2DS micro-pathologies are further consistent with the fact that none of the schizophrenia associated myelination genes (which include myelin-associated glycoprotein (MAG), myelin and lymphocyte protein (MAL), 2', $3^{\prime}$-cyclic nucleotide $3^{\prime}$-phosphodiestase (CNP), gelsolin, transferrin and HER3 (ErbB3) (Hakak et al., 2001)), are encoded in the 22q11.2 chromosomal region. On the contrary, several schizophrenia candidate genes which are found in the 22q11.2 chromosomal region, play a role in embryonic development or in the metabolism of neurotransmitters and mitochondria (Meechan et al., 2010). The list of such genes includes catechol-O-methyltransferase (COMT), proline dehydrogenase (PRODH), ubiquitin fusion degradation 1 protein (UFD1L), and Nogo66-receptor (RTN4R) (Meechan et al., 2010). The expression of these proteins in 22q11.2DS could therefore potentially result in changes in the development of WM, which are reflected by AD and FA measures. These abnormalities might constitute either: (1) risk factor (because of the increased risk of schizophrenia in 22q11.2DS), (2) protection factor (since none of our subjects was schizophrenic), or (3) an endophenotype that is different from "standard" schizophrenia (since, to date, RD changes rather than AD changes have been observed in schizophrenia). Further studies are needed to understand better the relationship between WM pathology and genetic risk factors for schizophrenia.

One of the limitations of this study is the relatively small sample size $(n=18)$. Despite the small sample size, however, the discriminant power is quite high $(99 \%)$, in part due to the state of the art technology used for the analysis, i.e., TBSS. A further limitation is the fact that the patients and their controls were not matched for IQ. Decreases in IQ are frequently considered part of the 22q11.2DS syndrome (Gothelf et al., 2007a) and for this reason samples were not corrected for IQ. Lastly, because of the cross-sectional nature of this study, no follow-up data was available. We thus do not know whether the 22q11.2DS subjects in this study will develop schizophrenia over time or not. Future follow up studies on 22q11.2DS patients, with and without schizophrenia, are needed to understand better the relationship between genes, risk for schizophrenia, and WM development. 
In summary, this is the first study to use TBSS to analyze patients with 22q11.2DS and matched healthy controls. Findings revealed reductions of FA and AD that were localized to WM in the left parietal lobe. RD changes were not observed. These findings suggest abnormalities in axonal integrity in 22q11.2DS subjects, rather than myelin disruption observed frequently in schizophrenia. Further, if 22q11.2DS is being used as a genetic model for schizophrenia, then our results suggest that WM developmental pathologies might predate schizophrenia, and in prospective studies $\mathrm{AD}$ and $\mathrm{RD}$ measures have the potential to distinguish between neurodevelopmental vs. neurodegenerative changes to WM microstructure in schizophrenia. Longitudinal, follow up studies that include converters should be performed to fully understand the dynamics of the relationship between those two pathologies.

\section{Acknowledgments}

We thank Dr. Ferenc Jolesz and the Department of Radiology at BWH for providing some of the funding for images for this pilot study.

\section{Role of funding source:}

The funding source had no role in study design, nor in the collection, analysis or interpretation of data, writing of the paper, or in the decision for publication.

\section{Funding:}

This work was supported, in part, by a NARSAD Young Investigator Award (ZK), by the Department of Veterans Affairs Merit Awards (MES), by a VA Schizophrenia Center grant (MES), by grants from the National Institute of Mental Health, including a Career Reentry Supplement (ZK) on R01 MH 50740 (MES), a K05 MH 070047 (MES), R01MH082918 (SB), and a NIH Mental Health Centers for Interventional Development and Applied ResearchCIDAR-P50 MH 080272 (MES, MK), and, finally, by the National Alliance for Medical Image Computing (NAMIC - U54 EB005149 (RK, also MK, MES), and a Neuroimage Analysis Center (NAC) P41 RR 13218 grant (RK) funded by NCRR.

\section{References}

Ashtari M, Cottone J, Ardekani BA, Cervellione K, Szeszko PR, Wu J, Chen S, Kumra S. Disruption of white matter integrity in the inferior longitudinal fasciculus in adolescents with schizophrenia as revealed by fiber tractography. Archives of general psychiatry. 2007; 64(11):1270-1280. [PubMed: 17984396]

Barnea-Goraly N, Lotspeich LJ, Reiss AL. Similar white matter aberrations in children with autism and their unaffected siblings: a diffusion tensor imaging study using tract-based spatial statistics. Archives of general psychiatry. 2010; 67(10):1052-1060. [PubMed: 20921121]

Barnea-Goraly N, Menon V, Krasnow B, Ko A, Reiss A, Eliez S. Investigation of white matter structure in velocardiofacial syndrome: a diffusion tensor imaging study. The American journal of psychiatry. 2003; 160(10):1863-1869. [PubMed: 14514502]

Basser PJ, Mattiello J, LeBihan D. Estimation of the effective self-diffusion tensor from the NMR spin echo. J Magn Reson B. 1994; 103(3):247-254. [PubMed: 8019776]

Bassett AS, Chow EW, Husted J, Weksberg R, Caluseriu O, Webb GD, Gatzoulis MA. Clinical features of 78 adults with 22q11 Deletion Syndrome. American journal of medical genetics. 2005; 138(4):307-313. [PubMed: 16208694]

Beaulieu C. The basis of anisotropic water diffusion in the nervous system - a technical review. NMR in biomedicine. 2002; 15(7-8):435-455. [PubMed: 12489094]

Carletti F, Woolley JB, Bhattacharyya S, Perez-Iglesias R, Fusar Poli P, Valmaggia L, Broome MR, Bramon E, Johns L, Giampietro V, Williams SC, Barker GJ, McGuire PK. Alterations in White Matter Evident Before the Onset of Psychosis. Schizophrenia bulletin. 2012

Chow EW, Ho A, Wei C, Voormolen EH, Crawley AP, Bassett AS. Association of schizophrenia in $22 q 11.2$ deletion syndrome and gray matter volumetric deficits in the superior temporal gyrus. The American journal of psychiatry. 2011; 168(5):522-529. [PubMed: 21362743] 
da Silva Alves F, Schmitz N, Bloemen O, van der Meer J, Meijer J, Boot E, Nederveen A, de Haan L, Linszen D, van Amelsvoort T. White matter abnormalities in adults with 22q11 deletion syndrome with and without schizophrenia. Schizophrenia research. 2011; 132(1):75-83. [PubMed: 21831603]

Davis KL, Stewart DG, Friedman JI, Buchsbaum M, Harvey PD, Hof PR, Buxbaum J, Haroutunian V. White matter changes in schizophrenia: evidence for myelin-related dysfunction. Archives of general psychiatry. 2003; 60(5):443-456. [PubMed: 12742865]

Deserno L, Sterzer P, Wustenberg T, Heinz A, Schlagenhauf F. Reduced prefrontal-parietal effective connectivity and working memory deficits in schizophrenia. The Journal of neuroscience: the official journal of the Society for Neuroscience. 2012; 32(1):12-20. [PubMed: 22219266]

Ellison-Wright I, Bullmore E. Meta-analysis of diffusion tensor imaging studies in schizophrenia. Schizophrenia research. 2009; 108(1-3):3-10. [PubMed: 19128945]

Faul F, Erdfelder E, Buchner A, Lang AG. Statistical power analyses using G*Power 3.1: tests for correlation and regression analyses. Behav Res Methods. 2009; 41(4):1149-1160. [PubMed: 19897823]

Giorgio A, Watkins KE, Chadwick M, James S, Winmill L, Douaud G, De Stefano N, Matthews PM, Smith SM, Johansen-Berg H, James AC. Longitudinal changes in grey and white matter during adolescence. NeuroImage. 2010; 49(1):94-103. [PubMed: 19679191]

Gothelf D, Feinstein C, Thompson T, Gu E, Penniman L, Van Stone E, Kwon H, Eliez S, Reiss AL. Risk factors for the emergence of psychotic disorders in adolescents with 22q11.2 deletion syndrome. The American journal of psychiatry. 2007a; 164(4):663-669. [PubMed: 17403981]

Gothelf D, Penniman L, Gu E, Eliez S, Reiss AL. Developmental trajectories of brain structure in adolescents with 22q11.2 deletion syndrome: a longitudinal study. Schizophrenia research. 2007b; 96(1-3):72-81. [PubMed: 17804201]

Green T, Gothelf D, Glaser B, Debbane M, Frisch A, Kotler M, Weizman A, Eliez S. Psychiatric disorders and intellectual functioning throughout development in velocardiofacial (22q11.2 deletion) syndrome. Journal of the American Academy of Child and Adolescent Psychiatry. 2009; 48(11):1060-1068. [PubMed: 19797984]

Gudbjartsson H, Maier SE, Mulkern RV, Morocz IA, Patz S, Jolesz FA. Line scan diffusion imaging. Magn Reson Med. 1996; 36(4):509-519. [PubMed: 8892201]

Hakak Y, Walker JR, Li C, Wong WH, Davis KL, Buxbaum JD, Haroutunian V, Fienberg AA. Genome-wide expression analysis reveals dysregulation of myelination-related genes in chronic schizophrenia. Proceedings of the National Academy of Sciences of the United States of America. 2001; 98(8):4746-4751. [PubMed: 11296301]

Harsan LA, Poulet P, Guignard B, Steibel J, Parizel N, de Sousa PL, Boehm N, Grucker D, Ghandour MS. Brain dysmyelination and recovery assessment by noninvasive in vivo diffusion tensor magnetic resonance imaging. J Neurosci Res. 2006; 83(3):392-402. [PubMed: 16397901]

Kates WR, Antshel KM, Faraone SV, Fremont WP, Higgins AM, Shprintzen RJ, Botti JA, Kelchner L, McCarthy C. Neuroanatomic predictors to prodromal psychosis in velocardiofacial syndrome (22q11.2 deletion syndrome): a longitudinal study. Biological psychiatry. 2011; 69(10):945-952. [PubMed: 21195387]

Kiehl TR, Chow EW, Mikulis DJ, George SR, Bassett AS. Neuropathologic features in adults with 22q11.2 deletion syndrome. Cereb Cortex. 2009; 19(1):153-164. [PubMed: 18483005]

Kirby ML, Gale TF, Stewart DE. Neural crest cells contribute to normal aorticopulmonary septation. Science (New York, N.Y. 1983; 220(4601):1059-1061.

Klawiter EC, Schmidt RE, Trinkaus K, Liang HF, Budde MD, Naismith RT, Song SK, Cross AH, Benzinger TL. Radial diffusivity predicts demyelination in ex vivo multiple sclerosis spinal cords. NeuroImage. 2011

Konrad A, Winterer G. Disturbed structural connectivity in schizophrenia primary factor in pathology or epiphenomenon? Schizophrenia bulletin. 2008; 34(1):72-92. [PubMed: 17485733]

Kubicki M, Maier SE, Westin CF, Mamata H, Ersner-Hershfield H, Estepar R, Kikinis R, Jolesz FA, McCarley RW, Shenton ME. Comparison of single-shot echo-planar and line scan protocols for diffusion tensor imaging. Academic radiology. 2004; 11(2):224-232. [PubMed: 14974598] 
Kubicki M, McCarley R, Westin CF, Park HJ, Maier S, Kikinis R, Jolesz FA, Shenton ME. A review of diffusion tensor imaging studies in schizophrenia. Journal of psychiatric research. 2007; 41(1-2):15-30. [PubMed: 16023676]

Mangin JF, Poupon C, Clark C, Le Bihan D, Bloch I. Distortion correction and robust tensor estimation for MR diffusion imaging. Med Image Anal. 2002; 6(3):191-198. [PubMed: 12270226]

Meechan DW, Maynard TM, Tucker ES, Lamantia AS. Three phases of DiGeorge/22q11 deletion syndrome pathogenesis during brain development: Patterning, proliferation, and mitochondrial functions of 22q11 genes. Int J Dev Neurosci. 2010

Melonakos ED, Shenton ME, Rathi Y, Terry DP, Bouix S, Kubicki M. Voxel-based morphometry (VBM) studies in schizophrenia-can white matter changes be reliably detected with VBM? Psychiatry research. 2011; 193(2):65-70. [PubMed: 21684124]

Murphy KC, Jones LA, Owen MJ. High rates of schizophrenia in adults with velo-cardio-facial syndrome. Archives of general psychiatry. 1999; 56(10):940-945. [PubMed: 10530637]

Murphy KC, Jones RG, Griffiths E, Thompson PW, Owen MJ. Chromosome 22qII deletions. An under-recognised cause of idiopathic learning disability. Br J Psychiatry. 1998; 172:180-183. [PubMed: 9519073]

Nagesh V, Tsien CI, Chenevert TL, Ross BD, Lawrence TS, Junick L, Cao Y. Radiation-induced changes in normal-appearing white matter in patients with cerebral tumors: a diffusion tensor imaging study. International journal of radiation oncology, biology, physics. 2008; 70(4):10021010 .

Niklasson L, Rasmussen P, Oskarsdottir S, Gillberg C. Autism, ADHD, mental retardation and behavior problems in 100 individuals with 22q11 deletion syndrome. Research in developmental disabilities. 2009; 30(4):763-773. [PubMed: 19070990]

Papolos DF, Faedda GL, Veit S, Goldberg R, Morrow B, Kucherlapati R, Shprintzen RJ. Bipolar spectrum disorders in patients diagnosed with velo-cardio-facial syndrome: does a hemizygous deletion of chromosome 22q11 result in bipolar affective disorder? The American journal of psychiatry. 1996; 153(12):1541-1547. [PubMed: 8942449]

Roosendaal SD, Geurts JJ, Vrenken H, Hulst HE, Cover KS, Castelijns JA, Pouwels PJ, Barkhof F. Regional DTI differences in multiple sclerosis patients. NeuroImage. 2009; 44(4):1397-1403. [PubMed: 19027076]

Rosenberger G, Kubicki M, Nestor PG, Connor E, Bushell GB, Markant D, Niznikiewicz M, Westin CF, Kikinis R, A JS, McCarley RW, Shenton ME. Age-related deficits in fronto-temporal connections in schizophrenia: a diffusion tensor imaging study. Schizophrenia research. 2008; 102(1-3):181-188. [PubMed: 18504117]

Seal ML, Yucel M, Fornito A, Wood SJ, Harrison BJ, Walterfang M, Pell GS, Pantelis C. Abnormal white matter microstructure in schizophrenia: a voxelwise analysis of axial and radial diffusivity. Schizophrenia research. 2008; 101(1-3):106-110. [PubMed: 18262770]

Shprintzen RJ. Velo-cardio-facial syndrome: 30 Years of study. Developmental disabilities research reviews. 2008; 14(1):3-10. [PubMed: 18636631]

Simon TJ, Wu Z, Avants B, Zhang H, Gee JC, Stebbins GT. Atypical cortical connectivity and visuospatial cognitive impairments are related in children with chromosome 22q11.2 deletion syndrome. Behav Brain Funct. 2008; 4:25. [PubMed: 18559106]

Smith SM, Jenkinson M, Johansen-Berg H, Rueckert D, Nichols TE, Mackay CE, Watkins KE, Ciccarelli O, Cader MZ, Matthews PM, Behrens TE. Tract-based spatial statistics: voxelwise analysis of multi-subject diffusion data. NeuroImage. 2006; 31(4):1487-1505. [PubMed: 16624579]

Song SK, Sun SW, Ju WK, Lin SJ, Cross AH, Neufeld AH. Diffusion tensor imaging detects and differentiates axon and myelin degeneration in mouse optic nerve after retinal ischemia. NeuroImage. 2003; 20(3):1714-1722. [PubMed: 14642481]

Song SK, Yoshino J, Le TQ, Lin SJ, Sun SW, Cross AH, Armstrong RC. Demyelination increases radial diffusivity in corpus callosum of mouse brain. NeuroImage. 2005; 26(1):132-140. [PubMed: 15862213]

Spitzer, R.; Williams, JBW.; Gibbson, M.; First, M. The structured clinical interview for DSM-III-Rnon-patient edition (SCID-NP). American Psychiatric Association; Washington, DC: 1990. 
Sundram F, Campbell LE, Azuma R, Daly E, Bloemen OJN. White matter microstructure in 22q11 deletion syndrome: a pilot diffusion tensor imaging and voxel-based morphometry study of children and adolescents. J of Neurodev Disorders. 2010; 2(2):77-92.

Tkachev D, Mimmack ML, Ryan MM, Wayland M, Freeman T, Jones PB, Starkey M, Webster MJ, Yolken RH, Bahn S. Oligodendrocyte dysfunction in schizophrenia and bipolar disorder. Lancet. 2003; 362(9386):798-805. [PubMed: 13678875]

Uranova N, Orlovskaya D, Vikhreva O, Zimina I, Kolomeets N, Vostrikov V, Rachmanova V. Electron microscopy of oligodendroglia in severe mental illness. Brain Res Bull. 2001; 55(5):597610. [PubMed: 11576756]

van Amelsvoort T, Daly E, Henry J, Robertson D, Ng V, Owen M, Murphy KC, Murphy DG. Brain anatomy in adults with velocardiofacial syndrome with and without schizophrenia: preliminary results of a structural magnetic resonance imaging study. Archives of general psychiatry. 2004; 61(11):1085-1096. [PubMed: 15520356]

Van Hecke W, Leemans A, Sijbers J, Vandervliet E, Van Goethem J, Parizel PM. A tracking-based diffusion tensor imaging segmentation method for the detection of diffusion-related changes of the cervical spinal cord with aging. J Magn Reson Imaging. 2008; 27(5):978-991. [PubMed: 18425838]

Wakana S, Caprihan A, Panzenboeck MM, Fallon JH, Perry M, Gollub RL, Hua K, Zhang J, Jiang H, Dubey P, Blitz A, van Zijl P, Mori S. Reproducibility of quantitative tractography methods applied to cerebral white matter. NeuroImage. 2007; 36(3):630-644. [PubMed: 17481925]

Whitford TJ, Kubicki M, Schneiderman JS, O’Donnell LJ, King R, Alvarado JL, Khan U, Markant D, Nestor PG, Niznikiewicz M, McCarley RW, Westin CF, Shenton ME. Corpus callosum abnormalities and their association with psychotic symptoms in patients with schizophrenia. Biological psychiatry. 2010; 68(1):70-77. [PubMed: 20494336] 
FA
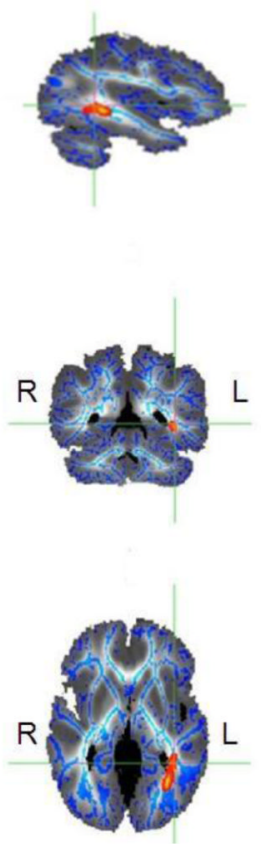

axial diffusivity
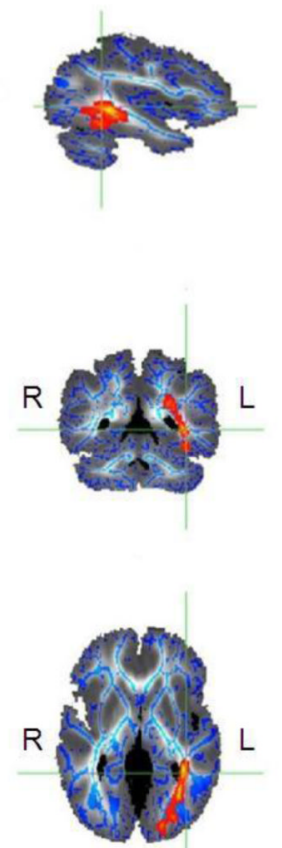

radial diffusivity
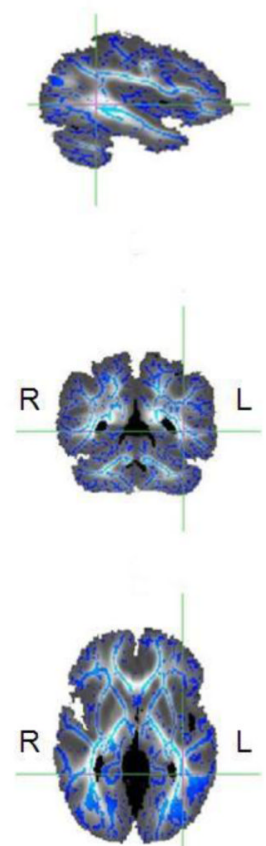

Fig. 1. Results of TBSS voxel-wise analysis of the cerebrum Reductions of voxel intensities in the 22q11.2DS group are indicated in red and yellow and represent $p$-values of $p<0.05$ corrected. The results are overlaid on the diffusion weighted image of one of the subjects (own target image) (image is presented in shades of gray and white); sagittal view on the top, coronal view in the middle and axial view at the bottom; the mean FA skeleton is represented in blue. The region of reductions of fractional anisotropy (FA) (panels on the left), reductions of axial diffusivity (AD) (panels in the middle) and lack of increases in radial diffusivity (RD)(panels on the right) are shown at the same coordinates marked by green lines. R: right hemisphere, L: left hemisphere. 

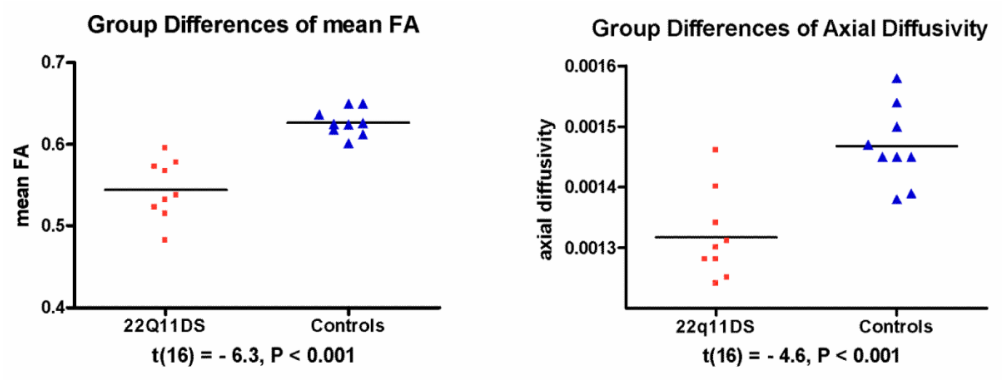

Fig. 2. Comparison of measures of diffusivity in the region of white matter reductions in the left hemisphere of the parietal lobe

The value of mean FA ranges between 0 (isotropic diffusivity) and 1 (anisotropic

diffusivity). The value of axial diffusivity is expressed in $\mathrm{mm}^{2} / \mathrm{s}$. The black bars indicate the means. The probabilities $\mathrm{t}$ and $\mathrm{P}$ are from independent-samples t-test. 


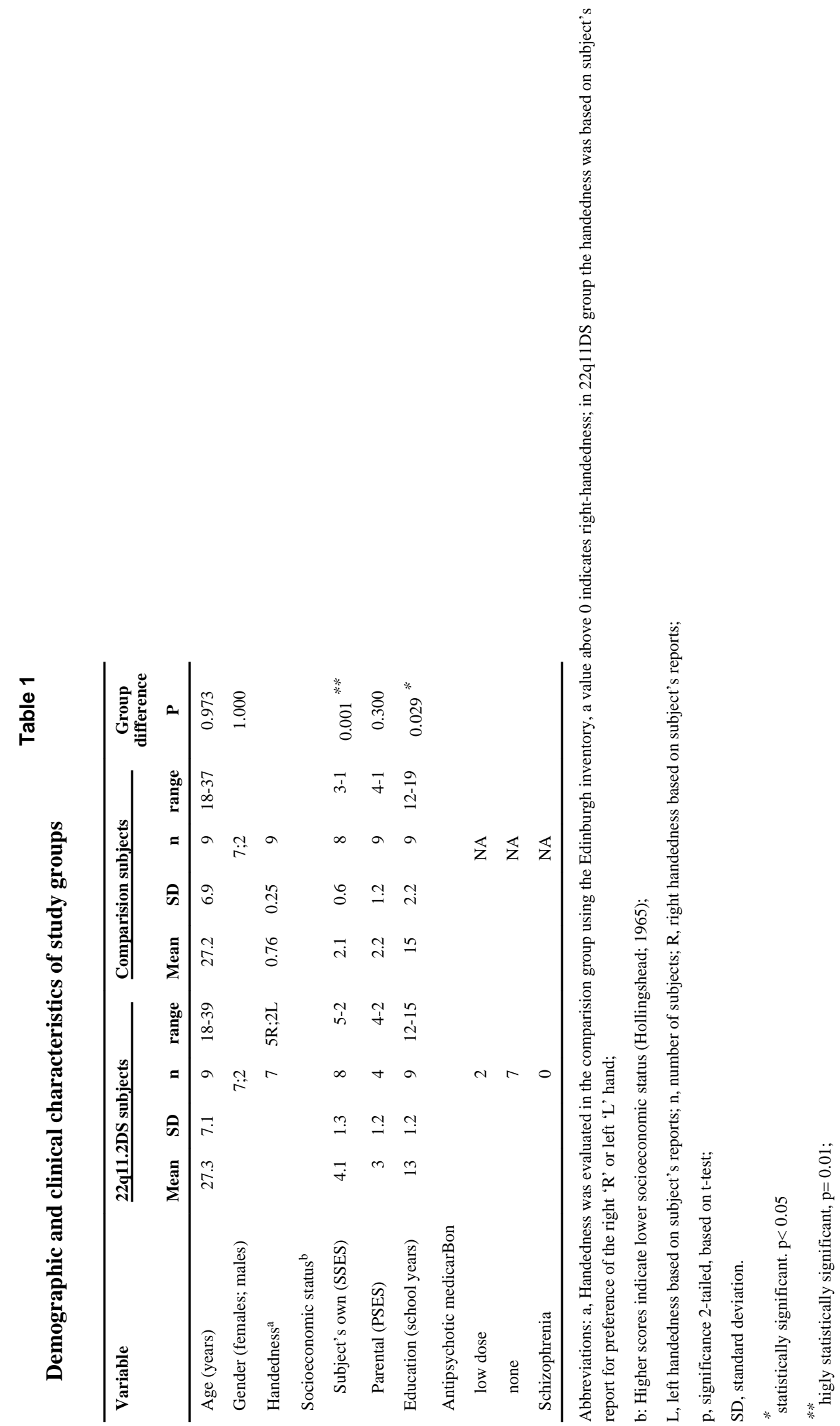

